\title{
INFORMATION SYSTEMS FOR ENVIRONMENTAL SUSTAINABILITY. HOW CAN COMPANIES CREATE A SUSTAINABLE AQUACULTURE INDUSTRY?
}

\author{
Carolina Costabile \\ Norwegian School of Economics, Helleveien 30, 5045 Bergen, Norway
}

\begin{abstract}
Environmental sustainability is among the main global challenges of the 21 st century. Although information systems that can provide data and insights about the status of the environment are considered valuable to better handle sustainability concerns, their potential is still not fully realized. Moreover, information systems research for sustainability is proceeding at a slow pace in relation to the real needs of our society. Therefore, this doctoral paper aims at embracing the urgent call for studies about sustainability from an Information Systems perspective. Through a case study in the Norwegian aquaculture industry, my work will contribute in understanding how companies can address environmental challenges by relying on digital technologies and their (IS-enabled) sensing, seizing, and recombining capabilities.
\end{abstract}

\section{KEYWORDS}

Information Systems, Environmental Sustainability, Dynamic Capabilities, Aquaculture

\section{INTRODUCTION}

Sustainability is internationally receiving increasingly attention from governments, consumers, organizations, and the whole society (Ziegler et al, 2013), which are all concerned in playing their role for a better world (Malhotra et al, 2013). Indeed, resources are currently being overused compared to what the nature can offer. And the way resources are being utilized is affecting the environment, often going towards a point of no return (Sarkis et al, 2013). The current environmental deterioration makes it clear why environmental sustainability initiatives are considerably popular across the world (Chen et al, 2009).

Information systems can be of pivotal importance in addressing environmental issues (Olson, 2008; Elliot, 2011; Malhotra et al, 2013; Seidel et al, 2017), and in affecting the success of these initiatives, especially because they can assess the status of the environment, and provide data and insights on which to make informed and appropriate decisions (Gholami et al, 2016). However, despite technology potential is broadly acknowledged, it is not fully exploited nor realized.

Therefore, I want to embrace the urgent call for solution-oriented studies directed towards information systems for sustainability (Gholami et al, 2016), and I want to give my contribution in solving environmental concerns in the aquaculture industry that is one of the sectors where challenges are extremely severe. Through a qualitative case study about a data lake initiative, I want to explore how companies can significantly address and progress towards environmental sustainability by relying on digital technologies and (IS-enabled) dynamic capabilities.

\section{BACKGROUND}

The World Commission on Environment and Development defined sustainability as the "development that meets the needs of the present without compromising the ability of the future generations to meet their own needs" (WECD, 1987, p.43). The concept involves environmental, social, and economic aspects. 
Environmental sustainability has been studied for decades in the field of operations, marketing and management, but not as much as needed as in the Information Systems field (Melville, 2010). Here, some studies have addressed the minimization of technology impacts on the environment (Green IT) and some others the enabling greening power of technology (Green IS) (vom Brocke et al., 2013), which is stronger when technology provides actionable knowledge (Gholami et al, 2016) about environment and business operations.

\subsection{Sustainability Challenges in the Norwegian Aquaculture Industry}

Aquaculture industry has pulled the Norwegian seafood industry (norwayexports.no, 2008) but has also raised concerns (Ziegler et al, 2013; Tveterås, 2002).

Indeed, after a decade of fast growth, aquaculture production volume has stagnated since 2012 because of, among other reasons, lice breakouts. Sea lice represents a big threat to wild salmon life and welfare together with escaped farmed salmon, which spreads diseases and parasites, and causes crossbreeds (Olaussen, 2018).

Another challenge that affects biological sustainability is pollution due to the high fish density in the cages, which results in faeces and undigested feed, and to the chemical treatments used to fight parasites (Olaussen, 2018). The whole industry must find a solution to the several and current challenges to stay competitive and to achieve a sustainable production of 5 million tons of salmon and trout by 2050 .

\subsection{Digital Technologies for Sustainability in the Aquaculture Industry}

Automation will play a key role for sustainability in the aquaculture industry.

Useful technologies are drones which may detect sea lice, monitor feeding process, maintain and repair net damages to prevent fish escapes (sintef.no, 2017), as well as IoT and Big Data analytics to collect, extract and analyze the massive daily amount of data that the industry produces.

The value extracted from data must not be considered as a source of competitive advantage for a single company, but something beneficial to the whole industry, since companies should jointly act to address the width of environmental sustainability that is far beyond a single organization (Watson et al, 2010).

It has been estimated that $85 \%$ of the aquaculture industry leaders is willing to invest in new technologies thanks to decreasing costs and time-to-market (PwC, 2017), showing times are ripe for leveraging on the technological transformative power in facing environmental issues.

\section{THE THEORETICAL FRAME}

Dynamic Capability theory gained popularity after the seminal article by Teece et al (1997) where dynamic capabilities were defined as the firm's ability to face evolving environments by integrating, building, and reconfiguring competencies.

Dynamic capabilities, as the name suggests, are not static as in the Resource-based view theory, and are essentially of three kinds: 1) sensing (and shaping) that refers to scan, create, and interpret new opportunities; 2) seizing that means addressing these opportunities; 3) reconfiguring that is related to assets recombination to face the changes in the environment and not to be constrained by well-known routines (i.e. path dependencies, Teece et al, 1997) (Teece, 2007). The theory highlights the role of managers who are supposed to find new and valuable combinations of resources both within and across the borders of their firm (Teece, 2007) in order to make its asset base not imitable (Teece, n.d.). 


\section{METHOD}

I will start my research with a literature review in order to gain an understanding of what has been discovered so far about my topic of interest.

Aiming at investigating how aquaculture companies choose and implement technologies (sensors, AI, Big Data Analytics), build and organize practices and processes to face environmental sustainability, I will study the AquaCloud platform which daily calculates the number of sea lice per fish in order to reduce sea lice infestations to environmentally sustainable levels (seafoodinnovation.no, 2017). I will study this data lake initiative from its launch in 2017 up to date by giving specific focus on how companies organize around and use technology within and across their borders to solve environmental sustainability issues.

A qualitative and longitudinal case study will allow me to comprehend how this initiative has emerged and developed over time, as well as to contribute to the development of a theory in its initial stage as Dynamic Capability (Helfat and Peteraf, 2009).

\subsection{Data Collection}

Data collection will be mainly based on semi-structured interviews.

In order to gather rich and quality data, I plan to interview different companies, and especially managerial and technical figures who are directly involved in AquaCloud development, architecture and governance, and who are key deciders about technology and sustainability.

Based on my theoretical lens, which will act as a guideline to access the empirical setting (Dubois and Gadde, 2002), I will design an interview protocol. I plan to collect information about environmental issues that need to be dealt with, motives that made companies join AquaCloud, technologies which have been put in place, and sharing attitude among the industry. On this last point, attention will be put on path dependencies (Teece et al, 1997), which may constrain the willingness to share data and collaborate among companies, and which may prevent the achievement of data harmonization and quality, important for the success of the whole initiative (seafoodinnovation.no, 2017). With the aim of uncovering sensing, seizing, and reconfiguring capabilities, I may ask about: how new opportunities are identified and technologies for environmental sustainability are chosen; how the identified opportunities are selected and executed, and how knowledge is shared; how changes in the environment are managed and to what extent data can improve the way sustainability is being addressed.

I will also try to investigate if new capabilities arise thank to the usage of technology (Singh et al, 2011). Data will be also collected through more objective sources as observations and archival data which will allow me to triangulate data coming from interviews.

\subsection{Data Analysis}

I plan to analyze data by using an abductive approach.

By going back and forth between theory, empirical world and case analysis, my first goal will be to discover core and recurrent themes in the data which refer to sensing, seizing and reconfiguring capabilities to address environmental sustainability with the use of technology. At first, the coding will reflect the participants' language as much as possible, so to ground my interpretation in the empirical context (Gioia et al, 2013). Then, a more abstract level will be reached, by combining the $1^{\text {st }}$ round findings with theory.

\section{CONCLUSION}

With my research, I am willing to contribute to a real problem and to help businesses tackle environmental sustainability by means of technology.

I plan to develop a framework with best practices and give practical examples of dynamic capabilities. Dynamic capabilities have not been fully well explained so far, and I may contribute by identifying the capabilities needed to exploit technology, how these capabilities are created, and what supports (e.g. technology) or hinders their development.

Limitations and personal biases, as well as ethical aspects will be taken into consideration. 


\section{REFERENCES}

Chen, A. et al, 2009. Organizational Adoption of Green IS \& IT: An Institutional Perspective. ICIS 2009 Proceedings, 142.

Dubois, A. and Gadde, L.E., 2002. Systematic combining: an abductive approach to case research. Journal of business research, 55(7), pp.553-560.

Elliot, S., 2011. Transdisciplinary perspectives on environmental sustainability: a resource base and framework for IT-enabled business transformation. MIS quarterly, 35(1), pp.197-236.

Gholami, R. et al, 2016. Information systems solutions for environmental sustainability: How can we do more?. Journal of the Association for Information Systems, 17(8), pp.521-536.

Gioia, D.A. et al, 2013. Seeking qualitative rigor in inductive research: Notes on the Gioia methodology. Organizational research methods, 16(1), pp.15-31.

Helfat, C.E. and Peteraf, M.A., 2009. Understanding dynamic capabilities: progress along a developmental path. Strategic Organization, 7 (1), pp.91-102.

Malhotra, A. et al, 2013. Spurring impactful research on information systems for environmental sustainability. MIS quarterly, 37(4), pp.1265-1274.

Melville, N.P., 2010. Information systems innovation for environmental sustainability. MIS quarterly, 34(1), pp.1-21.

Norwayexport.no, 2008. Norway's Fisheries: Healthy, Productive \& Sustainable. [online] Available at: <https://www.norwayexports.no/norways-fisheries-healthy-productive-sustainable/> [Accessed 10 December 2019].

Olaussen, J.O., 2018. Environmental problems and regulation in the aquaculture industry. Insights from Norway. Marine Policy, 98, pp.158-163.

Olson, E.G., 2008. Creating an enterprise-level "green" strategy. Journal of business strategy, 29(2), pp.22-30.

PwC, 2017. Sustainable growth towards 2050. PwC Seafood Barometer. [pdf] Available at: <https://www.pwc.no/no/publikasjoner/pwc-seafood-barometer-2017.pdf> [Accessed 20 March 2020].

Sarkis, J. et al, 2013. Green information systems \& technologies - this generation and beyond: Introduction to the special issue. Information Systems Frontiers, 15 (5), pp.695-704.

Seafoodinnovation.no, 2017. AquaCloud - The use of artificial intelligence in sea lice management. [online] Available at:

<http://www.seafoodinnovation.no/article/213/AquaCloud_The_use_of_artificial_intelligence_in_sea_lice_managem ent> [Accessed 10 December 2019].

Seidel, S. et al, 2017. The sustainability Imperative in Information Systems Research. Communications of the Association for Information Systems, 40 (3), pp.40-52.

Singh, R. et al, 2011. Dynamic capabilities in home health: IT-enabled transformation of post-acute care. Journal of the Association for Information Systems, 12 (2), pp.163-188.

Sintef, 2017. Tomorrow's fish farms will be unmanned. [online] Available at: https://www.sintef.no/en/latestnews/tomorrows-fish-farms-will-be-unmanned/ [Accessed 10 December 2019].

Teece, D.J., 2007. Explicating dynamic capabilities: the nature and microfoundations of (sustainable) enterprise performance. Strategic management Journal, 28(13), pp.1319-1350.

Teece, D.J., n.d. Dynamic Capabilities. [online] Available at: https://www.davidjteece.com/dynamic-capabilities [Accessed 20 March 2020].

Teece, D.J. et al, 1997. Dynamic capabilities and strategic management. Strategic management Journal, 18(7), pp.509-533.

Tveterås, S., 2002. Norwegian salmon aquaculture and sustainability: the relationship between environmental quality and industry growth. Marine Resource Economics, 17(2), pp.121-132.

vom Brocke, J. et al, 2013. Green Information Systems: Directives for the IS Discipline. Communication of the Association for the Information Systems, 33 (30), pp.509-520.

Watson, R.T. et al, 2010. Information systems and environmentally sustainable development: Energy informatics and new directions for the IS community. MIS quarterly, 34(1), pp.23-38.

World Commission on Environment and Development (WECD), 1987. Our Common Future: Report of the World Commission on Environment and Development.

Ziegler, F. et al, 2013. The carbon footprint of Norwegian seafood products on the global seafood market. Journal of Industrial Ecology, 17(1), pp.103-116. 